\title{
Intermeiocyte Connections and Cytomixis in Intergeneric Hybrid of Roegneria ciliaris (Trin.) Nevski with Psathyrostachys huashanica Keng
}

\author{
Chi Yen, Jun-Liang Yang and Gen-Lou Sun \\ Triticeae Research Institute, Sichuan Agricultural University Dujiangyang City, \\ Sichuan 611830, People's Republic of China
}

Accepted February 18, 1993

Psathyrostachys huashanica Keng is a native Triticeae species in central China. In order to study its biosystematic relationships with Roegneria ciliaris (Trin.) Nevski, another native Triticeae species in China, we observed the meiosis of their $F_{1}$ hybrid and found variations in both chromosome number per cell and cell size. The diminution of chromosome number by means of chromosome elimination is well known in wide hybrids. However, increase in number of chromosome of the pollen mother cells (PMCs) is uncommon. This phenomenon accompanied with multipolar division is similar to that in Iris japonica Thunb., a spontaneous plant widely distributed in Far East (Sinotô 1921, Yasui 1939). Cytomixis was described by Gate (1908) in Oenothera and then observed in many species and hybrids (a review see Whelan 1974). We supspected that cytomixis might also have occured in early stages of microsporogenesis in this hybrid. Thus, an extensive study on the microsporogenesis of this $F_{1}$ hybrid became necessary.

This paper reports the $F_{1}$ hybrid of $P$. huashanica with $R$. ciliaris and describes the observation of conjugation tube, conjugation opening, coenocytism, chromosome number diminution and multiplication, non-synchronous division, multipolar division and cytomixis in this $F_{1}$ hybrid. The significance of these processes in evolution is also discussed.

\section{Materials and methods}

Roegneria ciliaris (Trin.) Nevski (2n=28, SSYY) and Psathyrostachys huashanica Keng $\left(2 \mathrm{n}=14, \mathrm{~N}^{\mathrm{h}} \mathrm{N}^{\mathrm{h}}\right)$ used in this study were collected from eastern and central China, respectively. All these plant materials are maintained at Triticeae Research Institute, Sichuan Agricultural University.

Hybrids were made by pollinating hand-emasculated spikes of $R$. ciliaris with pollen of $P$. huashanica. Immature hybrid embryos were cultured on MS medium supplemented with coconut milk 14-16 days after pollination. The recovered hybrid seedlings were transplanted into pots when the seedlings reach the three leave stage.

For cytological study, young spikes of the $F_{1}$ hybrids were fixed in Carnoy's fluid. Chromosome numbers were counted at metaphase I of the PMCs. Microsporogenesis was studied on slides prepared by standared acetocarmine squashing. We used paraffin sectioning to avoid any physical changes of cell structure in squash preparations. Fixed young spike segments were stained with Snow's solution before dehydrated with standard alcohol method. Both cross and longitudinal sections were prepared and observed. Fresh untreated PMCs were also observed under contrast phase microscope for avoidance of the fixation and stain artifacts.

1 This work was financially supported in part by grants from IBPGR, FAO, UN and Chinese National Foundation for Natural Sciences. TRISAU Journal Series No. 6. 
Results and discussion

The intergeneric $F_{1}$ hybrids of $P$. huashanica with $R$. ciliaris are theoretically expected to have 21 chromosomes. The majority of the PMCs observed coincided with these expectation (Table 1, Fig. 1). Table 2 shows the meiotic data of the normal $F_{1}$ hybrids and their parents, indicating that $P$. huashanica share no common genome with either $R$. ciliaris. However, as shown in Table 1, unusual chromosome numbers were observed.

In the $R$. ciliaris $\times P$. huashanica $\mathrm{F}_{1}$ hybrid (Fig. 1), seven large chromosomes should come from the male parent and 14 chromosomes from the female parent. However, the chromosome number varied greatly in PMCs of these hybrids (Table 1). For the $R$. ciliaris $\times P$.

Table 1. Chromosome number per cell and its frequency at MI of pollen mother cells of Roegneria ciliaris with Psathyrostachys huashanica $\mathrm{F}_{1}$ hydrid

\begin{tabular}{ccc}
\hline Chromosome number & no. cells observed & $\%$ \\
\hline 15 & - & - \\
16 & 1 & 2.78 \\
17 & 1 & 2.78 \\
18 & 3 & - \\
20 & - & 66.67 \\
21 & 24 & - \\
22 & - & 2.78 \\
24 & 1 & 5.56 \\
25 & 2 & 2.78 \\
26 & 1 & - \\
27 & - & - \\
28 & - & - \\
29 & - & - \\
30 & - & - \\
33 & 1 & 2.78 \\
36 & - & - \\
42 & 1 & - \\
47 & - & - \\
49 & - & - \\
51 & - & - \\
54 & - & - \\
56 & - & - \\
62 & - & - \\
66 & - & - \\
67 & - & - \\
70 & - & - \\
78 & - & - \\
100 & & - \\
& & - \\
\hline
\end{tabular}

huashanica hybrid, $33 \%$ of the PMCs observed had the chromosome number varying from 8 (Fig. 2) to 70 (Fig. 3). Coenocytes of this hybrid often showed non-synchronous division (Fig. 4). At anaphase II of the PMCs of the $R$. ciliaris $\times P$. huashanica hybrid, multipolar division was observed (Fig. 5, 6).

Chromosome elimination is not a rare phenomenon in wide hybrids. However, a wide renge of chromosome number variation in one hybrid involving both diminution and multiplicătion is uncommon, especially when accompanied with coenocytism (Fig. 7).

We examined the early stages of the microsporogenesis in the $R$. ciliaris $\times P$. huashanica hybrids and discovered that microsporocytes did not lined up as a mass of cells. They were loosely arranged and conjugated (Table 3 ) together by two kinds of special struc- 

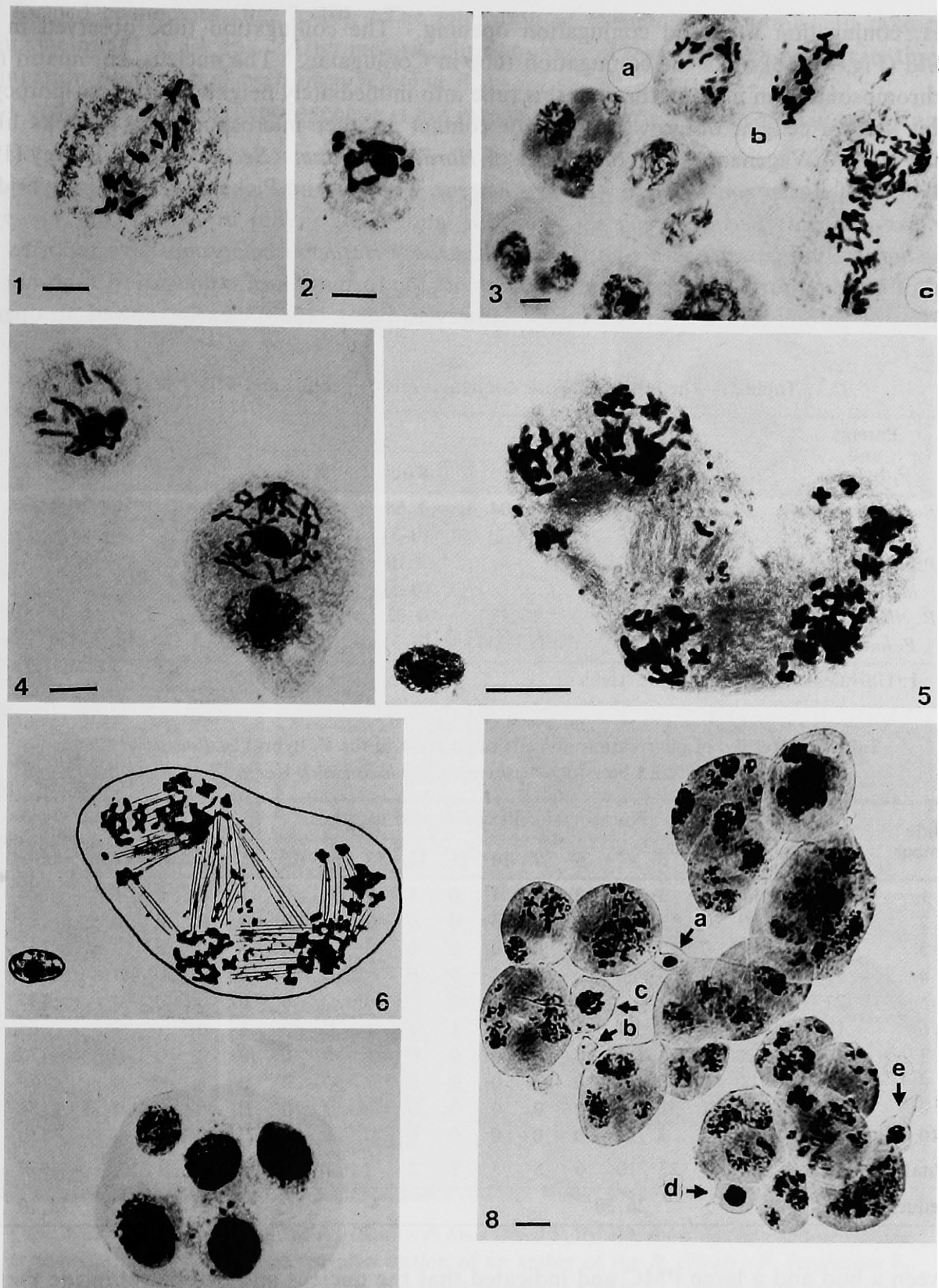

Figs. 1-8. 1, A nomal PMC of the $R$. Ciliaris $\times P$. huashanica $\mathrm{F}_{1}$ hybrid, showing 21 univalents. 2 , A small PMC of the $R$. ciliaris $\times P$. huashanica $F_{1}$ hybrid, showing 9 chromosomes and chromosome segments. 3 , PMCs of the $R$. ciliaris $\times P$. huashanica $F_{1}$ hybrid, showing 18 chromosomes (Cell a), 21 chromosomes (Cell b) and 70 chromosomes (Cell c). 4, Two PMCs of the $R$. ciliaris $\times P$. huashanica $\mathrm{F}_{1}$ hybrid, showing non-synchronous division (large) and chromosome diminution (small). 5, Multipolar division of the $R$. ciliaris $\times P$. huashanica $\mathrm{F}_{1}$ hybrid, showing anaphase II. 6, A diagram of Fig. 5, showing the relationship among the 12 poles. 7, A coenocyte with 5 nuclei observed in the $R$. ciliaris $\times P$. huashanica $\mathrm{F}_{1}$ hybrid. 8 , The PMCs of the $R$. cliliaris $\times P$. huashanica $F_{1}$ hybrid with conjugation tubes (arrowed) and coenocytes, showing transfer of chromatin through the tube (a), a tube that was broken during slide preparation (b) and tubes that did not contact with the neighboring cell and thus formed a bud-like outgrowth $(\mathrm{c}, \mathrm{d}, \mathrm{e}) . \mathrm{Bar}=10 \mu \mathrm{m}$. 
tures: conjugation tube and conjugation opening. The conjugation tube observed in this hybrid (Fig. 8) looks like the conjugation tube in Conjugatae. The nucleus, chromatin mass or chromosomes can migrate through this tube into immediately neighboring microsporocytes. If this kind of cellular outgrowth does not contact another microsporocyte, it looks like a bud (Fig. 8). Wagenaar (1959) in hybrids of Hordeum jubatun $\times$ Secale cereale, Dewey (1967) in hybrids of Agropyron scribneri $\times$ Elymus junceus, Thomas and Pickering (1979) in hybrids of Hordeum vulgare $\times$ Secale cereale cv. 'Rheidol' and Wang (1988) in hybrids of Thinopyron elongatum $\times$ Psathyrostachys juncea, Lymus angustus $\times$ Hordeum bulbosum, have reported this kind of budding formation. They did not report the formation of conjugation tube nor the transfer of chromatin through this tube. However, Wang (1988) clearly showed an opening

Table 2. The normal meiotic configurations of parents and $F_{1}$ hybrids.

\begin{tabular}{|c|c|c|c|c|c|c|}
\hline \multirow{2}{*}{$\begin{array}{c}\text { Parents } \\
\text { and } \\
F_{1} \text { hybrids }\end{array}$} & \multirow{2}{*}{$\begin{array}{c}\text { Number of } \\
\text { cells } \\
\text { observed }\end{array}$} & \multirow{2}{*}{ I } & \multicolumn{2}{|c|}{ II } & \multirow{2}{*}{ III } & \multirow{2}{*}{$\begin{array}{c}\text { Chiasmata } \\
\text { per cell }\end{array}$} \\
\hline & & & Rods & Rings & & \\
\hline Roegneria ciliaris & 53 & $\begin{array}{l}0.04 \\
(0-2)\end{array}$ & $\begin{array}{l}1.68 \\
(0-5)\end{array}$ & $\begin{array}{l}12.38 \\
(9-14)\end{array}$ & - & 26.44 \\
\hline $\begin{array}{c}\text { Psathyrostachys } \\
\text { huashanica }\end{array}$ & 37 & - & $\begin{array}{l}3.19 \\
(0-5)\end{array}$ & $\begin{array}{l}3.81 \\
(1-7)\end{array}$ & - & 10.81 \\
\hline $\begin{array}{l}\text { R. ciliaris } \times \\
\quad P \text {. huashanica }\end{array}$ & 66 & $\begin{array}{l}20.33 \\
(15-21)\end{array}$ & $\begin{array}{l}0.32 \\
(0-3)\end{array}$ & - & - & 0.32 \\
\hline
\end{tabular}

I: Univalent; II: bivalent; III: trivalent.

Table 3. Results of observation on cell conjugation in the $F_{1}$ hybrid of Roegneria ciliaris (Trin.) Nevski $\times$ Psathyrostachys huashanica Keng

\begin{tabular}{crrrrrrrrrrrrrrrrrrrrrr}
\hline \multirow{2}{*}{$\begin{array}{c}\text { Slide } \\
\text { number }\end{array}$} & \multicolumn{1}{c}{} & 2 & 3 & 4 & 5 & 6 & 7 & 8 & 9 & 10 & 11 & 12 & 13 & 14 & 15 & 16 & 17 & 21 & 24 & $\begin{array}{c}\text { Non- } \\
\text { conjugated } \\
\text { cells }\end{array}$ \\
\hline 1 & 28 & 10 & 14 & 4 & 3 & 2 & 3 & 1 & 1 & 0 & 1 & 0 & 1 & 0 & 1 & 0 & 0 & 1 & 84 \\
2 & 11 & 7 & 6 & 4 & 3 & 2 & 0 & 0 & 3 & 0 & 0 & 0 & 0 & 0 & 0 & 0 & 0 & 0 & 212 \\
3 & 24 & 14 & 6 & 6 & 2 & 1 & 2 & 0 & 0 & 0 & 0 & 0 & 0 & 0 & 1 & 0 & 0 & 0 & 131 \\
4 & 17 & 12 & 8 & 3 & 5 & 0 & 0 & 0 & 1 & 0 & 0 & 0 & 0 & 0 & 1 & 0 & 0 & 0 & 131 \\
5 & 27 & 18 & 5 & 3 & 2 & 1 & 0 & 1 & 0 & 0 & 0 & 0 & 0 & 0 & 0 & 0 & 0 & 0 & 137 \\
6 & 18 & 11 & 3 & 1 & 1 & 1 & 1 & 2 & 0 & 1 & 1 & 1 & 0 & 0 & 1 & 0 & 1 & 0 & 64 \\
7 & 30 & 10 & 5 & 4 & 2 & 1 & 0 & 0 & 0 & 0 & 0 & 1 & 0 & 0 & 0 & 0 & 0 & 0 & 175 \\
8 & 29 & 13 & 8 & 3 & 1 & 0 & 0 & 1 & 0 & 0 & 0 & 0 & 0 & 0 & 0 & 0 & 0 & 0 & 152 \\
9 & 17 & 6 & 3 & 1 & 1 & 0 & 0 & 0 & 0 & 0 & 0 & 0 & 0 & 0 & 0 & 0 & 0 & 0 & 134 \\
10 & 14 & 9 & 9 & 6 & 3 & 2 & 0 & 0 & 0 & 0 & 0 & 0 & 0 & 0 & 0 & 0 & 0 & 0 & 150 \\
Total & 215 & 111 & 67 & 35 & 23 & 10 & 6 & 5 & 5 & 1 & 2 & 2 & 1 & 0 & 4 & 0 & 1 & 1 & 1370 \\
\hline
\end{tabular}

between a bud and a large PMC and indicated that the nucleus and cytoplasm inside the bud were originated from the large PMC. In addition to the formation of conjugation tubes, neighboring microsporocytes may stick out cone-like structures oppositely and conjoin to one another. Openings are formed at these conjoined points. Nuclei (Fig. 9, 10, 11), chromosomes (Fig. 12, 14), chromonemata (Fig. 15) and small amount of chromatin mass (Fig. 8) can then migrate through these openings. We suggest to call this kind of opening as conjugation opening. A conjugation opening has the same function as a conjugation tube, but they differ in morphology. If the chromatin mass migrate through the opening as small as plasmodesma, this is cytomixis (Fig. 13) has been reported by many authors. In this hybrid, we observed the resting stage nuclei of pre-meiotic PMCs can migrate through the conjugation tube or opening 
and formed coenocytes (fig. 7, 10). The migration of chromatin materials can take place during meiosis (Fig. 14, 15). After meiosis, chromosomes of the pollen grains migrate through conjugation opening had been observed (Fig. 12).

Coenocytism in microsporogenesis is not rate in intergeneric hybrids in Triticeae (Kagawa
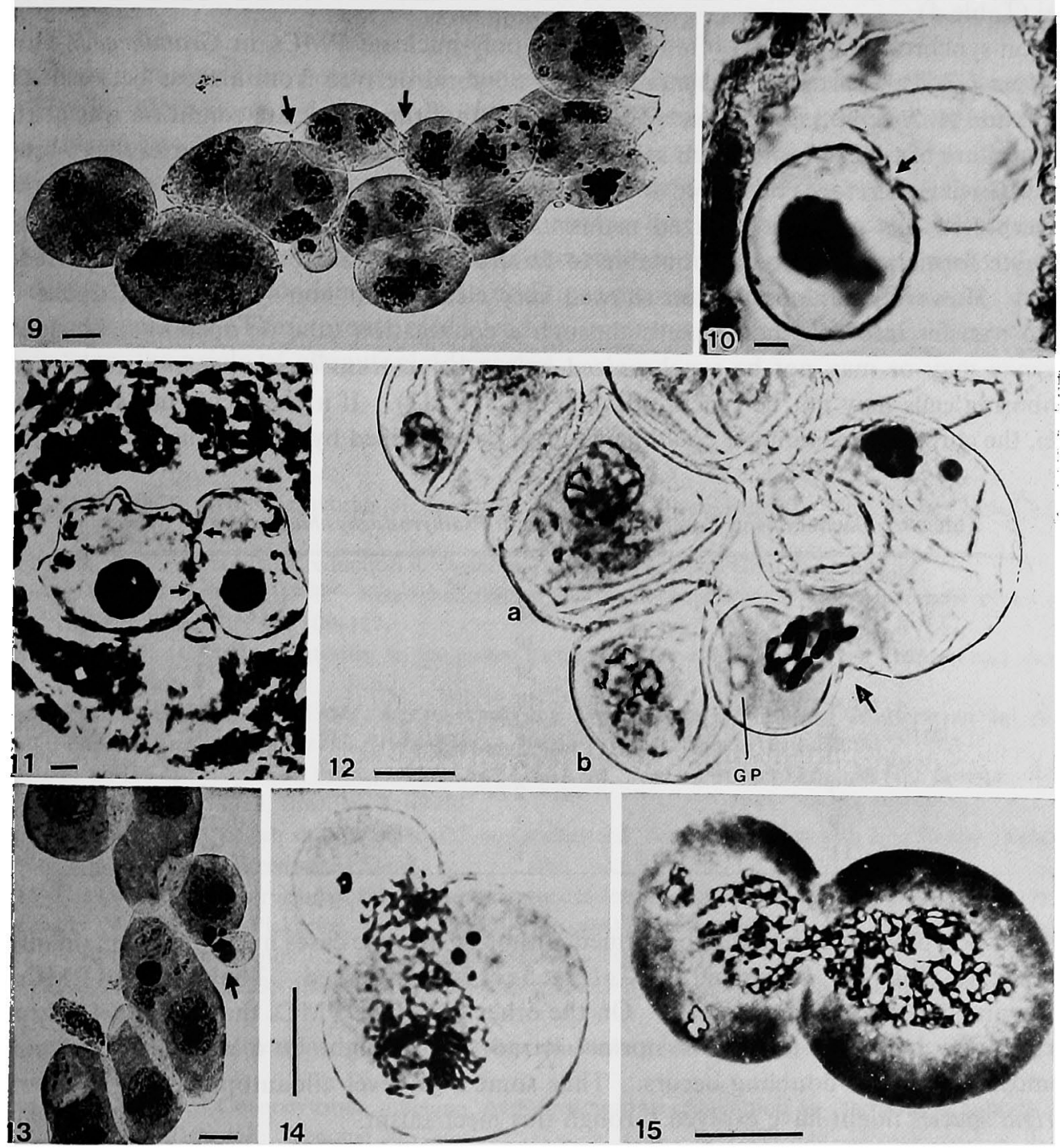

Figs. 9-15. 9, The PMCs of the R. ciliaris $\times P$. huashanica $\mathrm{F}_{1}$ hybrid, showing conjugation opening (arrowed). 10, A longitudinal paraffin section of an anther of the $R$. ciliaris $\times P$. huashanica $\mathrm{F}_{1}$ hybrid, showing a conjugation opening (arrowed) between two PMCs. All the protoplasm in the upper shrunken empty cell had transferred into the lower cell. 11, A contrast-phase-microscopic picture of a paraffin cross section of an anther of the $R$. ciliaris $\times P$. huashanica $\mathrm{F}_{1}$ hybrid, showing two conjugation tubes between two single nucleus microsporocytes. 12, The young pollen grains of the $R$. ciliaris $\times P$. huashanica $\mathrm{F}_{1}$ hybrid, showing a group of univalents were transferring through the conjugation opening (arrowed). The young pollen grains a and b showing two nuclei. $\mathrm{GP}$ is a germ pore of the pollen grain $\mathrm{b} . \quad 13$, The PMCs of the $R$. ciliaris $\times P$. huashanica $\mathrm{F}_{1}$ hybrid, showing cytomixis (arrowed). 14, The PMCs of the $R$. ciliaris $\times P$. huashanica $\mathrm{F}_{1}$ hybrid, showing the transfer of a prophase nucleus through a conjugation opening. 15, Two untreated PMCs of the $R$. ciliaris $\times P$. huashanica $\mathrm{F}_{1}$ hybrid observed under contrast phase microscope, showing transfer of chromonemata through conjugation opening. $\operatorname{Bar}=10 \mu \mathrm{m}$. 
1929, Kihara and Lilienfeld 1943, Villax and Mota 1953, Nakajima 1954a, b). Coenocytism will lead to the formation of pseudomicrospores in nondehiscent anthers. Wang (1988) reported coenocytism in the $P$. huashenica $\times$ Secale montanum hybrids and observed an average of 4.44 nuclei, range from 2 to 25 per PMC. In the present study, 19.92\% of the PMCs observed in the $R$. ciliaris $\times P$. huashanica hybrids were found to be coenocytes contaning 2 to 11 nuclei (Table 4).

Non-synchronized meiosis often occurs in poly-nucleate PMCs in Gramineae. Holden and Mota (1958) reported this phenomenon in a hybrid derived from a cross between Avena barbata and $A$. strigosa ssp. hirtula. They believed that the binucleate condition was attributable to failure of cell wall formation at the premeiotic mitosis and the two nuclei they observed in a PMC were therefore considered to be identical. Consequently, they and the cited others misinterpreted this non-synchronized meiosis. Doubtlessly, the basis of the mechanism of coenocyte formation may be attributable to failure of cell wall formation at the premeiotic mitosis. However, our observation showed very clearly that non-synchronized nuclei were able to transfer into neighboring cells through a conjugation tube or opening. Nuclei in a coenocyte may or may not be synchronized before being transferred, because nuclei among neighboring cells may not be synchronized (Figs. 8, 9, 13). If a coenocyte has synchronized nuclei, the chromosome number could be doubled or redoubled by nucleus fusion and a unified

Table 4. Coenocytes in Roegneria ciliaris with Psathyrostachys huashanica $\mathbf{F}_{1}$ hybrids

\begin{tabular}{ccc}
\hline \hline Nuclei per cell & no. cell & $\%$ \\
\hline 1 & 390 & 81.08 \\
2 & 30 & 6.24 \\
3 & 24 & 4.99 \\
4 & 17 & 3.53 \\
5 & 8 & 1.66 \\
6 & 8 & 1.66 \\
7 & 2 & 0.42 \\
9 & 1 & 0.21 \\
11 & 1 & 0.21 \\
\hline
\end{tabular}

high level polyploid nucleus could be formed, although in some cases nuclei may remain infused in coenocytes (Fig. 7). Decaploid PMCs (Fig. 3: c) were observed. The decaploid PMCs can from pentaploid tetrad after meiosis. On the other hand, the PMCs that contain 42 chromosomes (Table 1) should form four normal tetrad. This might be a way that spontaneous chromosome number doubling occurs. Thus some high level alloautopolyploid Leymus and Elytrigia species might have evolved through this mechanism.

If the transfer of a nucleus into a neighboring cell is not complete, aneuploid PMCs will result.

Cytomixis was also observed in the pre-meiotic cells of the $R$. ciliaris $\times P$. huashanica hybrids (Fig. 13). It was however rare in comparison with cell-to-cell transfer of chromatin masses, chromosomes and nuclei through conjugation tube or opening.

Multipolar division, which occurred in this hybrid, might be caused by the multipolar zones of synchronized nuclei in a coenocyte. We speculate that this kind of PMCs cannot form normal tetrad and have to degenerate eventually. Conversely, synchronized nuclei in a few PMCs might form normal tetrad which followed normal bipolar division, as in the spontaneous hybrid Iris japonica, where $0.35 \%$ capsules were found to have two normal and five abnormal seeds (Yen and Yang, unpublished data). We believe that the perennial hybrids derived from the cross combinations in the present study should produce a few fertile gametes. 
If this is true, the spontaneous chromosome doubling and redoubling might have occurred. It might be one of the pathways of speciation in Triticeae. Such a pathway could have led to the origin of a high level polyploid such as L. angustus. We believe that the mechanism of chromatin transfer through cell conjugation is a common alternative of chromosome doubling.

\section{Summary}

Key words: conjugation, coenocytism, evolution, multipolar division, non-synchronization.

The $\mathrm{F}_{1}$ intergeneric hybrids of Psathyrostachys huashanica Keng with Roegneria ciliaris (Trin.) Nevski was made and cytologically studied. Chromatin transfer through conjugation tube or conjugation opening before, during and after meiosis was observed in these hybrids. Consequently, unusual nuclear behaviors frequently observed include coenocytism, cell size variation and abnomal chromosome or nuclei number, non-synchronous or multipolar division, and delayed chromatin condensation. In addition, cytomixis was observed in early stages of micro-sporogenesis. These events could lead to spontaneous chromosome number doubling and, in turn, the origin of alloautoploid species.

\section{References}

Dewey, D. R. 1967. Synthetic hybrids of Agropyron scribneri X Elymus junceus. Bull. Torrey Bot. Club. 94: 388-395.

Gates, R. R. 1908. A study of reduction in Oenothera rubrinervis. Bot. Gaz. 46: 1-34.

Holden, J. W. and M. Mota. 1958. Non-synchronized meiosis in binucleate pollen mother cells of an Avena hybrid. Heredity 10: 109-117.

Kagawa, F. 1929. Cytological studies on the pollen formation of the hybrids between Triticum and Aegilops. Jap. J. Bot. 4: 345-361.

Kihara, H. and F. Lilienfeld, 1934. Kerneiwanderung und bildung syndipolider Mutterzeren bei dem $F_{1}$ Bastard Triticum aegilopoides $\times$ Aegilops squarrosa. Jap. J. Genet. 10: 1-28.

Nakajima, G. 1954a. Genetical and cytological studies in the breeding of amphidiploid type between Triticum and Secale. Jap. J. Breeding 3: 47-52.

- . 1954b. Meiosis of pollen mother cells of $T$. compactum $\times S$. cereale $\mathrm{F}_{2}$ plants with $2 \mathrm{n}=56$ and 58 chromosomes. Jap. J. Breeding 3: 53-58.

Sinotô, Y. 1921. On the extrusion of the nuclear substance in Iris japonica Thunb. Bot. Mag. Tokyo 35: 178-195.

Thomas, H. M. and R. A. Pickering, 1979. Barley $x$ ryc crosses, the morphology and cytology of the hybrids and the amphidiploids. Z. Pflanzenzücht 82: 193-200.

Villax, E. and M. Mota, 1953. Behavior of a Triticum $\times$ Secale hybrid under the action of colchicine. Nature 172: 412.

Wagenaar, E. B., 1959. Intergeneric hybrids between Hordeum jubatum L. and Secale cereale L.. J. Hered. 50: $192-202$.

Wang, R. R-C. 1988. Coenocytisma, ameiosis, and chromosome diminution in intergeneric hybrids in the perennial Triticeae. Genome 30: 766-775.

Whelan, E. D. P. 1974. Discontinuities in the callose wall, intermeiocyte connection, and cytomixis in angiosperm meiocytes. Can. J. Bot. 52: 1219-1223.

Yasui, K. 1939. Karyological studies on Iris japonica Thunb. and its allies. Cytologia 10: 180-188. 